\title{
Synthesis and characterization of castor oil-based polyurethane for potential application as host in polymer electrolytes
}

\author{
S IBRAHIM ${ }^{1 * *}$, A AHMAD ${ }^{2}$ and N S MOHAMED ${ }^{3}$ \\ ${ }^{1}$ Institute of Graduate Studies, University of Malaya, 50603 Kuala Lumpur, Malaysia \\ ${ }^{2}$ School of Chemical Sciences and Food Technology, Faculty of Science and Technology, \\ Universiti Kebangsaan Malaysia, 46300 Bangi, Selangor, Malaysia \\ ${ }^{3}$ Center for Foundation Studies in Science, University of Malaya, 50603 Kuala Lumpur, Malaysia
}

MS received 21 January 2014; accepted 20 May 2015

\begin{abstract}
Polyurethane (PU) based on polyol, derived from castor oil has been synthesized and characterized for potential use as a base material for electrolytes. Transesterification process of castor oil formed a polyol

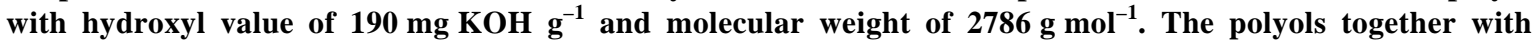
4,4'-diphenylmethane diisocyanate were used to synthesize the desired bio-based PU. The molecular structure of PU was investigated by Fourier transform infrared (FTIR) spectroscopy. The disappearance of NCO peak in the FTIR spectrum at $2270-2250 \mathrm{~cm}^{-1}$ showed that diisocyanate has completely reacted to form PU. Morphological characteristic of the PU film was analysed using scanning electron microscopy, whereas thermal characteristics of the materials were characterized using dynamic mechanical analysis and thermal gravimetric analysis. The cross-sectional micrograph showed that the prepared film was highly amorphous and homogeneous. Thermal studies revealed that the film had low glass transition temperature, $-15.8^{\circ} \mathrm{C}$, and was thermally stable up to $259^{\circ} \mathrm{C}$. These observations indicated the synthesized PU possessed favourable properties to act as a base material in polymer electrolytes.
\end{abstract}

Keywords. Castor oil; transesterification; polyol; 4,4'-diphenylmethane diisocyanate; polyurethane.

\section{Introduction}

Polyurethanes (PUs) are versatile materials and widely used in both industry and everyday life. They can be used for many applications, such as tubings, footwear, industrial machinery, coatings and paints, elastic fibres, rigid insulations, soft flexible foam, medical devices, and many others. ${ }^{1-3}$ PUs are included in both thermoplastic and thermosetting polymers. Research and development in the field of PUs is increasing year to year showing the rapid growth in PU industry. The polymers are mainly produced by the isocyanation of diisocyanate (NCO) with polydiol $(\mathrm{OH})$ of various molecular weights. ${ }^{4}$ Large selections of polyols and isocyanates are available, which permit the design of polymers for many applications. PUs serve the mankind in its various roles such as flexible, rigid, semi-rigid, elastomers, surface coatings, and adhesives. A review on the background and history of urethane foams and elaborations on their potential future utility has been written by Khemani. ${ }^{5}$

The properties of PU depend on certain factors such as the content of the reactive groups, the degree of crosslinking and the entanglement of the reacting monomers.

\footnotetext{
*Author for correspondence (salmiah01@gmail.com)
}

In order to meet specific requirement, their structures can be tailored by selecting appropriate polyols and polyisocyanates. In industry, only a few diisocyanates or polyisocyanates are commonly used, while a variety of polyols are available. Therefore, the choice of polyol typically determines the properties of the created PUs. ${ }^{6}$ In addition to petroleum-based polyols, vegetable oils such as soybean oil, canola oil, palm oil, sunflower oil, corn oil, linseed oil and nahar seed oil ${ }^{7-9}$ have been extensively studied as bases for various polyols used for the manufacture of PUs for different applications.

The preparation of polymers from vegetable oils is currently receiving increasing attention because of the economic and environmental concerns. ${ }^{10-13}$ Raw materials based on vegetable oils have a number of excellent properties for producing valuable polymers such as PU, alkyd, polyester, amide and epoxy resins. Vegetable oils are triglycerides of fatty acids. In order to use these compounds as starting materials for PU synthesis, it is necessary to functionalize them to form polyols. Castor oil (Ricinus communis) from the family of Euphorbiaceae is a promising starting raw material for PU due to low toxicity and availability as a renewable agricultural resources. The major constituent in the castor oil is ricinoleic acid (12-hydroxy-cis-9-octadecenoic acid), which is a hydroxyl containing fatty acid. The most common 
chain lengths in these fatty acids are 18 and 20 carbon atoms which can be either saturated or unsaturated, where unsaturation of the double bonds are located at the 9,12 , and 15 carbon. By using enzymes or chemicals to modify the unsaturated fatty acid and introducing hydroxyl functional groups, castor oils could be converted into polyol. There are many literatures on modified castor oil PU for application in bridge decking, adhesives and thermal insulation. ${ }^{14-16}$ However, modification of PU for use as host in polymer electrolytes has not yet been reported in the literature. PU has unique multiphase structure formed from soft segment and hard segment in the polymer chains. Soft segment could contribute as polymeric solvent to solvate the cation and hard segment could function in maintaining the electrochemical stability. Therefore, it would be used as PU polymer electrolytes in the fabrication of electrochemical devices. ${ }^{17}$

The aim of this work is to synthesize PU from renewable resource, castor oil with desired properties for application as host material in polymer electrolytes as an alternative to petrochemical-based PU. Nevertheless, there is no report related to the potential of castor oil-polyolbased PU as host in polymer electrolytes. The synthesis is carried out at room temperature without additives, cross linkers and chain extenders. The work comprises of the transesterification of castor oil followed by polymerization of PU. The materials were characterized including optical, morphological and thermal properties. Although there are many methods and sources to synthesize PU, the transesterification of polyol from castor oil could give highly amorphous PU with low molecular weight and low glass transition temperature, $T_{\mathrm{g}}$, value. Unlike crystalline phase, the polymeric chain in the amorphous phase is more flexible, which results in enhancement of segmental motion to enable easy ion migration.

\section{Experimental}

\subsection{Materials}

Castor oil, glycerol (99.9\%), ethanol (99\%), methanol, potassium hydrogen phthalate, phthalate anhydride, potassium hydroxide, phenolphthalein and tetrahydrofuran (THF) were supplied by R\&M Marketing, Essex, UK, while 4,4'-diphenylmethane diisocyanate (MDI) and lithium iodide (LiI) were obtained from Merck and Aldrich, respectively. All the reagents were of analytical grade and used without further purification.

\subsection{Preparation of castor oil-based PU films}

The PU films were obtained by two steps of procedures. In the first step, the castor oil was modified to obtain polyol of desired acid value and in the subsequent step it was reacted with MDI to obtain flexible films. Transesterification of castor oil was performed under nitrogen atmosphere. The set-up consisted of four-necked glass reactor of $1000 \mathrm{ml}$ capacity with $250 \mathrm{~mm}$ height and $150 \mathrm{~mm}$ in diameter equipped with a mechanical stirrer. Heating was carried out by means of $1000 \mathrm{ml}$ heating mantle. Nitrogen was supplied at a constant flow rate to avoid any oxidation reaction within the reactor. One of the necks of the reactor was equipped with a reflux condenser. The reactor was filled with castor oil and $15 \mathrm{wt} \%$ of glycerol was added to it. The percentage of the mixture was fixed according to the Patton formula ${ }^{18}$ to obtain the hydroxyl value of below $200 \mathrm{mg} \mathrm{KOH} \mathrm{g}^{-1}$. The mixture was slowly heated until it reached $210^{\circ} \mathrm{C}$. The temperature was maintained at this value under constant stirring at $200 \mathrm{rpm}$. The small amount of reaction mixture was taken out and mixed with methanol in the ratio of $1: 4$ to check the solubility of the mixtures. A clear and homogeneous solution was obtained, indicating the formation of monoglycerides. The mixture was allowed to cool to $120^{\circ} \mathrm{C}$ before it was latter continuously stirred at $\sim 200$ $220^{\circ} \mathrm{C}$ after the addition of an appropriate amount of phthalate anhydride. The progress of condensation reaction and its stability were confirmed by checking its acid value according to the procedure recommended in ASTM D1639-90E. For this purpose, samples were taken out at regular intervals and checked for an acid value using the titration method and phenolphthalein was used as indicator. The time required to complete the reaction was about $10 \mathrm{~h}$. The resulted polyol was stored in dark bottles away from direct sun light. The produced polyol was mixed thoroughly with MDI using a digital magnetic stirrer at room temperature condition in the weight percentage (wt\%) ratios of $20: 80(\mathrm{NCO}: \mathrm{OH})$ and $40: 60(\mathrm{NCO}: \mathrm{OH})$. MDI was slowly added to polyol and THF was used as the solvent. The complete reaction of PU was confirmed by the disappearance of NCO peak at $2270 \mathrm{~cm}^{-1}$ in Fourier transform infrared (FTIR) spectra. The resulting solution was poured into a Teflon mould and left for slow evaporation of solvent. To ensure complete curing, the films produced were kept in a desiccator before they were characterized. For polymer electrolytes preparation, composition of $\mathrm{NCO}: \mathrm{OH}$ that formed $\mathrm{PU}$ was dissolved in $10 \mathrm{ml}$ THF before the addition of lithium iodide in different wt $\%$ (10-40 wt $\%)$ and stirred for $4 \mathrm{~h}$. The homogeneous solutions were then casted in Teflon Petri dishes and left at room temperature for slow drying until freestanding films were obtained.

\subsection{Analytical measurements}

The interaction of chemical structures of polyol and PU prepared using castor oil was characterized using Perkin-Elmer Frontier FTIR/MIR spectrophotometer through attenuated total reflectance (ATR) scanning from 
550 to $4000 \mathrm{~cm}^{-1}$ with a resolution of $2 \mathrm{~cm}^{-1}$. The molecular weight, $M_{\mathrm{w}}$, of polyol and PU-based castor oil was determined by the gel-permeation chromatography (GPC) technique using the Waters equipment with refractive index detector, Water 717 plus Autosampler and Water 600 Controller. THF was used as the eluent with flow rate of $1 \mathrm{ml} \mathrm{min}^{-1}$ at 16 bar. Dynamic mechanical analysis (DMA) was performed in order to determine the glass transition temperature, $T_{\mathrm{g}}$, of the synthesized PU. The analysis was performed using Perkin Elmer DMA 8000 dynamic mechanical analyser with a film-tension mode of $1 \mathrm{~Hz}$. Rectangular PU film specimens of $20 \times 10 \times$ $0.60 \mathrm{~mm}$ (length $\times$ thickness $\times$ width) were used for the analysis. The samples were cooled and held isothermally at $-60^{\circ} \mathrm{C}$ before the temperature was increased to $180^{\circ} \mathrm{C}$ at a rate of $2^{\circ} \mathrm{C} \mathrm{min}^{-1} . T_{\mathrm{g}}$ values of the samples were obtained from the peaks of the $\tan \delta$ curves. The thermogravimetric analysis (TGA) was carried out in order to study thermal stability of the PU films. The TGA was done using the Setaram LABSYS Evo simultaneous thermal analyser. The experiment was carried out under nitrogen atmosphere from 30 to $600^{\circ} \mathrm{C}$ at $10^{\circ} \mathrm{C} \mathrm{min}^{-1}$ heating rate. The morphology of the cross-section of polymer films was observed using ZEISS EVO MA 10 scanning electron microscope at $\times 2000$ magnification with $10 \mathrm{kV}$ electron beam. Sample was fractured and coated with gold using sputter coating machine for $90 \mathrm{~s}$ before the analysis. Conductivity measurements of the polymer electrolytes were done using impedance spectroscopy, Solartron SI 1260 impedance/Gain-Phase Analyser. The measurements were performed over frequency range of $10 \mathrm{~Hz}-5 \mathrm{MHz}$ with amplitude of $100 \mathrm{mV}$ at room temperature. The samples were sandwiched by two polished stainless-steel blocking electrodes. The values of bulk resistance, $R_{\mathrm{b}}$, of the electrolytes were determined from the Nyquist plots obtained. Conductivity, $\sigma$ values were calculated using equation

$$
\sigma=\frac{t}{R_{\mathrm{b}} A}
$$

where $t$ is the thickness of the electrolyte and $A$ the electrolyte-electrode contact area.

\section{Results and discussion}

Scheme 1 shows the transesterification of castor oil-based polyol. Esterification began after phthalate anhydride was added to the mixture of oil and glycerol and after sometime, water was collected and the mixture turned into a clear brownish solution. From the titration that was done at a certain interval of time during the heating and stirring processes, the calculated acid value of the reaction was found to decrease gradually throughout the reaction. This proves that the reaction has progressed and polyester polyol was formed. The polyol obtained has an acid value of $3 \mathrm{mg} \mathrm{KOH} \mathrm{g}{ }^{-1}$. The hydroxyl value of the polyol was obtained using 848 Titrino Plus equipment and its value is $190 \mathrm{mg} \mathrm{KOH} \mathrm{g}^{-1}$. According to Petrovic, polyols with $\mathrm{OH}$ numbers of about $200 \mathrm{mg} \mathrm{KOH} \mathrm{g}^{-1}$ and less give semi-rigid PUs of moderate or low crosslinking density when crosslinked with diisocyanate. ${ }^{19}$ Figure 1 shows FTIR<smiles>[R]C(=O)OCC1COC(=O)OCC1[P]</smiles>

Castor oil<smiles>[R]C(=O)COC(O)CO</smiles>

$+$
Glycerol

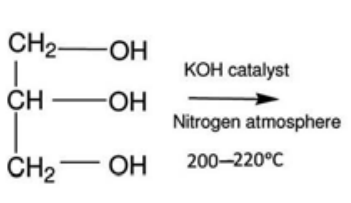

I<smiles>[R]C(=O)OCC(O)CO</smiles>

Monoglyceride<smiles>O=C1OCC(CO)OC(=O)O1</smiles>

Diglyceride
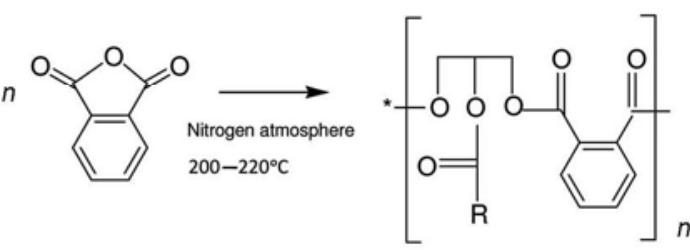

Monoglyceride

Pthalic anhydride

Polyol

where<smiles>[R]CCCCC(O)CC=CCCCC</smiles>

Scheme 1. Schematic representation of the preparation of castor oil-based polyol. 
spectra of castor oil and synthesized castor oil-based polyol. The characteristic band of ester group $\mathrm{C}=\mathrm{O}$ stretching appears at $1730 \mathrm{~cm}^{-1}$ and that of $\mathrm{O}-\mathrm{H}$ functional group at $3550 \mathrm{~cm}^{-1}$. These bands confirm the esterification reaction of polyol.

As mentioned earlier, PU films were produced by the reaction of MDI with castor oil-based polyol. Two different PU formulations were used (table 1). Formulation 1 contains $\mathrm{NCO}$ and $\mathrm{OH}$ in the weight ratio of $20: 80$, while Formulation 2 contains $\mathrm{NCO}: \mathrm{OH}$ ratio of $40: 60$. Figure 2 presents the FTIR spectra of the synthesized castor oilbased PU in the region $550-4000 \mathrm{~cm}^{-1}$. For Formulation 2 , the presence of peak at $2270 \mathrm{~cm}^{-1}$ indicates that the isocyanate has not completely reacted. The absence of peak at $2270 \mathrm{~cm}^{-1}$ is an indicative of the absence of NCO groups in the structure of Formulation 1 (NCO:OH $(20: 80))$. On the other hand, new peaks at 1512 and $3369 \mathrm{~cm}^{-1}$ corresponding to $-\mathrm{NH}$ vibration $(-\mathrm{NH}-\mathrm{C}=\mathrm{O}-)$ and absorbance band around $1740 \mathrm{~cm}^{-1}$ characteristic of the $\mathrm{C}=\mathrm{O}$ group are present in the FTIR spectra. ${ }^{20}$ According to Narine et $a l,{ }^{21}$ the band around $1740 \mathrm{~cm}^{-1}$ indicates that the hydrogen bonded $\mathrm{C}=\mathrm{O}$ group vibration region is overlapped with the free $\mathrm{C}=\mathrm{O}$ group vibration region. The absence of the isocyanate peak and appearance of amine and carbonyl peaks indicate a complete conversion of monomers to urethane. ${ }^{22-24}$ Therefore, for further investigation, only Formulation 1 was used. It is referred as PU in the following paragraphs. The photograph of castor oil-based PU film is shown in figure 3.

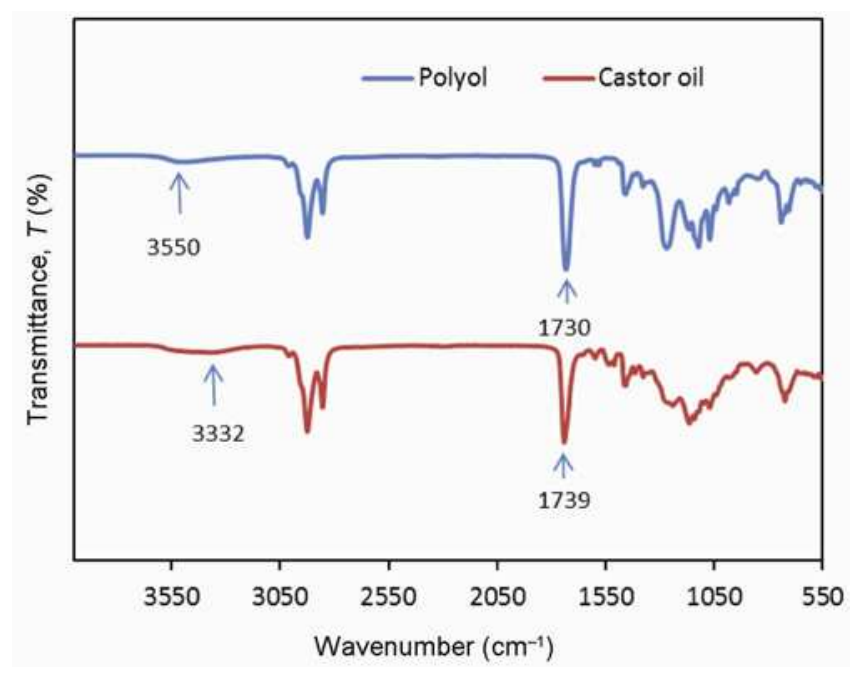

Figure 1. FTIR spectra of castor oil and polyol.

Table 1. Weight ratio of $\mathrm{NCO}: \mathrm{OH}$ in different formulations.

\begin{tabular}{lcc}
\hline Formulation & NCO :OH & Physical observation \\
\hline 1 & $20: 80$ & Soft and flexible \\
2 & $40: 60$ & Rigid and brittle \\
\hline
\end{tabular}

In this work, molecular weight of samples was determined by using gel-permeation chromatography. From the chromatogram that was not shown here, the molecular weight of castor oil is $1023 \mathrm{~g} \mathrm{~mol}^{-1}$, close to the value reported by other researcher which is $963 \mathrm{~g} \mathrm{~mol}^{-1} .^{14}$ The synthesized castor oil-based polyol gives a molecular weight of $2786 \mathrm{~g} \mathrm{~mol}^{-1}$. This value is suitable to form flexible PU. ${ }^{25,26}$ The molecular weight of synthesized PU in this work is $11,942 \mathrm{~g} \mathrm{~mol}^{-1}$. Table 2 summarizes the molecular weight of samples.

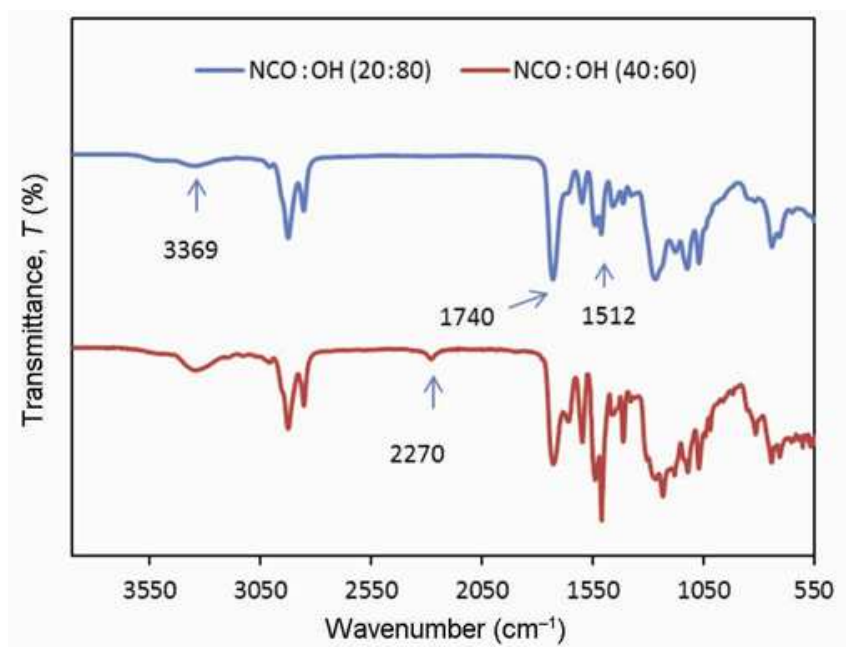

Figure 2. FTIR spectra of castor oil-based polyurethane.

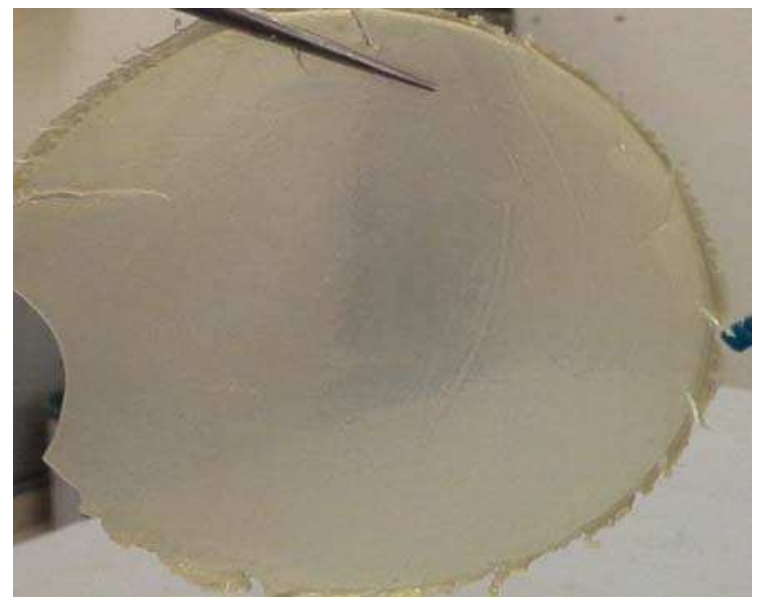

Figure 3. Photograph of castor oil-based polyurethane film.

Table 2. Values of molecular weight of castor oil, polyol and polyurethane.

\begin{tabular}{lc}
\hline Sample & Molecular weight, $M_{\mathrm{w}}\left(\mathrm{g} \mathrm{mol}^{-1}\right)$ \\
\hline Castor oil & 1023 \\
Polyol & 2786 \\
Polyurethane & 11,942 \\
\hline
\end{tabular}


Table 3. Decomposition temperatures, $T_{\mathrm{d}}$ and percentage weight losses of polyurethane film.

\begin{tabular}{|c|c|c|c|c|}
\hline \multicolumn{3}{|c|}{ Weight loss (\%) } & \multirow{2}{*}{$\begin{array}{l}\text { Total weight } \\
\text { loss }(\%)\end{array}$} & \multirow{2}{*}{$\begin{array}{c}\text { Residue after } \\
600^{\circ} \mathrm{C}(\%)\end{array}$} \\
\hline$T_{\mathrm{d} 1} 258-330^{\circ} \mathrm{C}$ & $T_{\mathrm{d} 2} 313-430^{\circ} \mathrm{C}$ & $T_{\mathrm{d} 3} 410-560^{\circ} \mathrm{C}$ & & \\
\hline 4.7 & 47.7 & 34.8 & 87.2 & 12.8 \\
\hline
\end{tabular}

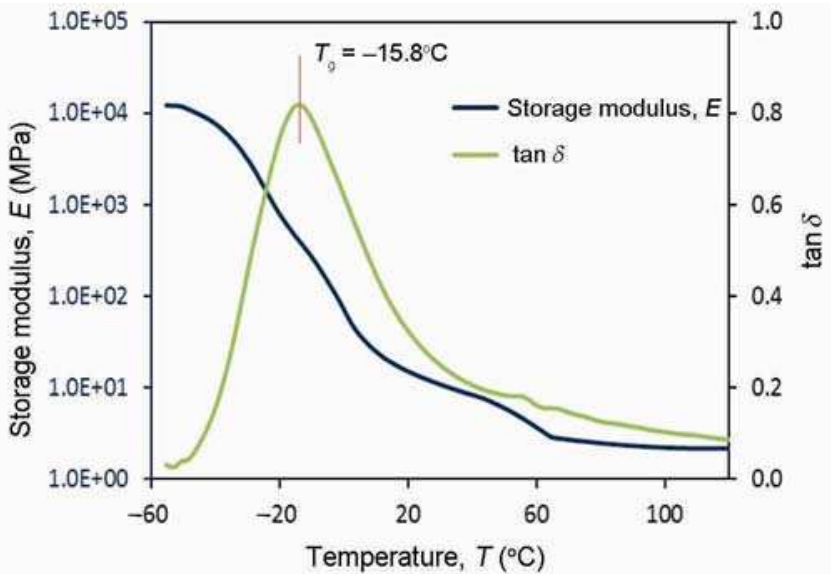

Figure 4. Tangent delta and storage modulus as a function of temperature for polyurethane.

Figure 4 depicts the plot of storage modulus, $E$ and $\tan \delta$ vs. temperature of PU film. $E$ is slightly decreased from -60 to $-40^{\circ} \mathrm{C}$, then decreases rapidly after $-40^{\circ} \mathrm{C}$ until a rubbery plateau is observed in higher temperature. This change corresponds to glass-rubber transition and $\tan \delta$ reaches its maximum peak simultaneously. The plot shows one $\tan \delta$ peak, indicating homogeneous nature of the film. The value of glass transition temperature, $T_{\mathrm{g}}$, is given by the peak maximum ( $\alpha$ relaxation) of $\tan \delta v s$. temperature curve. The $T_{\mathrm{g}}$ value obtained for the PU film is $-15.8^{\circ} \mathrm{C} . T_{\mathrm{g}}$ values of PUs are depending on the properties of the synthesized polyols, therefore the values could vary from -50 to $80^{\circ} \mathrm{C}$. Júnior et al reported the value of thermoplastic PU based on castor oil is $-30^{\circ} \mathrm{C}$ whereas Liu and co-workers ${ }^{27}$ obtained a $T_{\mathrm{g}}$ value of $22.3^{\circ} \mathrm{C}$ for castor oil-based PU. On the other hand, Yeganeh and Shamekhi ${ }^{28}$ obtained values of $T_{\mathrm{g}}$ between 47 and $61^{\circ} \mathrm{C}$ for the PUs synthesized from different compositions of castor oil and glycolysed poly(ethylene terphthalate) (PET).

Illustrated in figure 5 are thermogravimetric and derivatives of thermogravimetric curves for PU. Three decomposition stages are observed. Table 3 lists the decomposition temperatures, $T_{\mathrm{d}}$, and the percentage weight loss after decompositions. The first degradation stage, $T_{\mathrm{d} 1}$, is observed at $259^{\circ} \mathrm{C}$ which achieves a maximum temperature, $T_{\max }$, at $271^{\circ} \mathrm{C}$. The $T_{\mathrm{d} 1}$ is corresponding to the degradation of urethane linkages. From the first degradation stage, it can be concluded that the film is

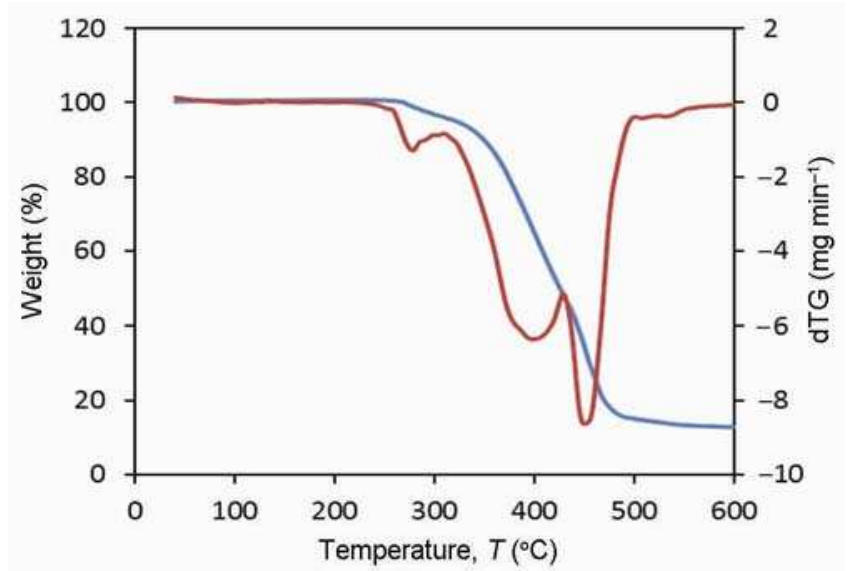

Figure 5. Thermogravimetric and derivative thermogravimetric curves of polyurethane.

thermally stable from room temperature until the temperature started to decompose. The second step of thermal degradation, $T_{\mathrm{d} 2}$, is observed from $313^{\circ} \mathrm{C}$ up to $400^{\circ} \mathrm{C}$. The third step of thermal degradation, $T_{\mathrm{d} 3}$, begins at 429 to $550^{\circ} \mathrm{C}$. $T_{\mathrm{d} 2}$ corresponds to the liberation of free isocynate and $T_{\mathrm{d} 3}$ is attributed to the decomposition of soft segment of the PU. ${ }^{29,30}$ The TGA result suggests that the PU is stable from ambient temperature up to $259^{\circ} \mathrm{C}$.

The morphology of cross-sectional area of the castor oil-based PU film is shown in figure 6. As seen in the figure, the film is smooth and no phase separation is observed. The smooth morphology of the film shows that the film is highly amorphous. This characteristic is favourable for a host of polymer electrolytes as ion conduction occurs in amorphous region.

In order to determine whether the synthesized PU can be used as host in polymer electrolytes, a doping salt, LiI has been added to the biopolymer. The plot of conductivity of PU polymer electrolytes with the addition of salt is illustrated in figure 7 . The conductivity of pristine PU is $1.18 \times 10^{-11} \mathrm{~S} \mathrm{~cm}^{-1}$ increased to $4.92 \times$ $10^{-8} \mathrm{~S} \mathrm{~cm}^{-1}$ with the addition of only $10 \mathrm{wt} \% \mathrm{LiI}$. The conductivity increased by three orders of magnitudes compared to pristine $\mathrm{PU}$ and reached maximum value up to $1.42 \times 10^{-6} \mathrm{~S} \mathrm{~cm}^{-1}$ upon the addition of $30 \mathrm{wt} \%$ of LiI. Further addition of salt resulted in a decrease in conductivity. The increase in conductivity was contributed by the number of conducting species in the electrolyte caused by dissociation of LiI ions. This occurred due to 


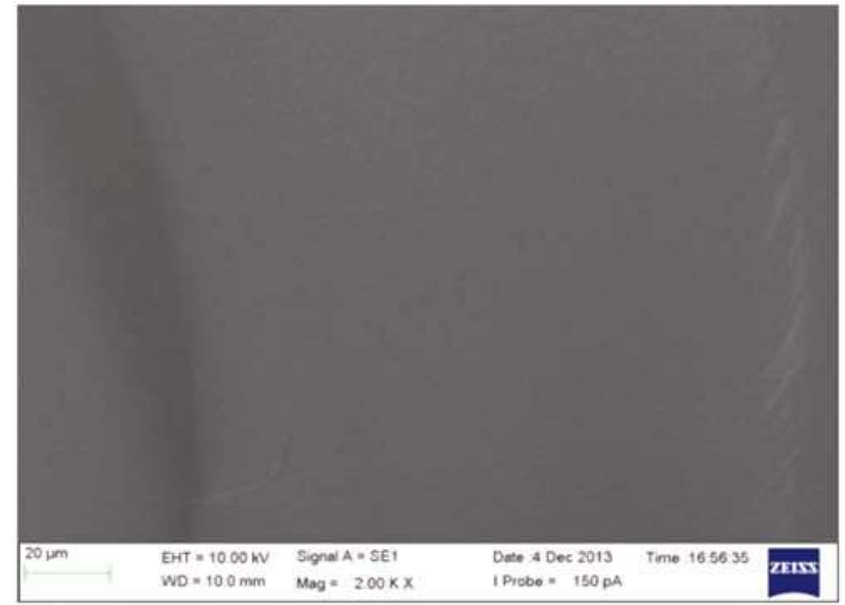

Figure 6. SEM image of cross-section of castor oil-based polyurethane film.

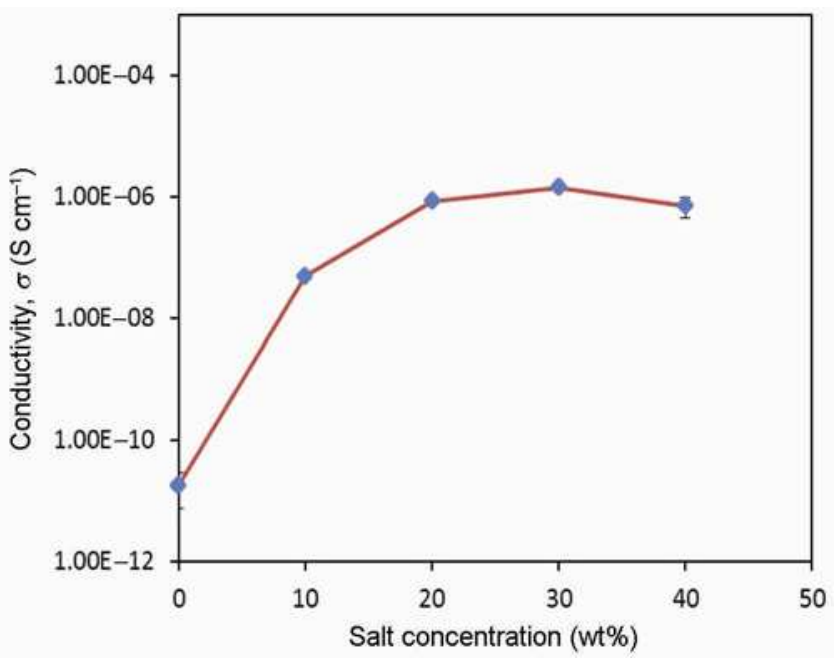

Figure 7. Conductivity of castor oil-based polyurethane with the addition of different wt $\%$ of lithium iodide.

the presence of coordinating atoms in the polymer host. The conducting species or free mobile ions present in the polymer may increase the amorphous structure, thus eases the ion migration. The decrease in conductivity after optimum value is probably due to ion association or ion aggregation. ${ }^{31,32}$

\section{Conclusions}

A castor oil-based polyol was successfully synthesized via transesterification. The polyol has an acid value of $3 \mathrm{mg} \mathrm{KOH} \mathrm{g}^{-1}$ and $\mathrm{OH}$ number of $190 \mathrm{mg} \mathrm{KOH} \mathrm{g}^{-1}$. Using this polyol, PU was successfully synthesized as confirmed by FTIR results. The film prepared using the synthesized PU demonstrated highly amorphous, low $T_{\mathrm{g}}$ value of $-15.8^{\circ} \mathrm{C}$ and was free standing as well as good thermal stability, up to $259^{\circ} \mathrm{C}$. The $\mathrm{PU}$ shows a conductivity value upon the addition of salt up to $1.42 \times$ $10^{-6} \mathrm{~S} \mathrm{~cm}^{-1}$ with the addition of $30 \mathrm{wt} \%$ of LiI. These results indicated that the castor oil-based PU possessed favourable properties for the application as host in polymer electrolytes.

\section{Acknowledgements}

We are grateful to the University of Malaya for financial support under Postgraduate Research Fund, PPP Grant no. PG073/2012B. A highly gratitude goes to the Ministry of Education, Malaysia for the scholarship under the Graduate Scheme Program MyBrain15 given to Salmiah Ibrahim.

\section{References}

1. Chattopadhyay D K and Webster D C 2009 Prog. Polym. Sci. 341068

2. Szycher M 2013 Szycher's handbook of polyurethanes (ed.) M Szycher (Boca Raton: CRC Press, Taylor \& Francis) 2nd ed, p 2

3. Firdaus M and Meier M A R 2013 Green Chem. 15370

4. Hepburn C 1992 Iran J. Polym. Sci. Technol. 184

5. Khemani K C 1997 Polymeric foams science and techno$\operatorname{logy}$ (ed.) K C Khemani (Washington DC: ACS Symposium Series) $\mathrm{p} 1$

6. Pfister D P, Xia Y and Larock R C 2011 ChemSusChem. 4 703

7. Louwrier A 1998 Biotechnol. Appl. Biochem. 271

8. Dutta N, Karak N and Dolui S K 2004 Prog. Org. Coat. 49 146

9. Badri K H, Othman Z and Ahmad S H 2004 J. Mater. Sci. 395541

10. Alfani R, Iannace S and Nicolais L 1998 J. Appl. Polym. Sci. 68739

11. Petrovic Z S, Zhang W and Javni I 2005 Biomacromolecules 6713

12. Uyama H, Kuwabara M, Tsujimoto T, Nakano M, Usuki A and Kobayashi S 2003 Chem. Mater. 152492

13. Mutlu H and Meier M A R 2010 Eur. J. Lip. Sci. Technol. 11210

14. Somani K P, Kansara, S S, Patel N K and Rakshit A K 2003 Int. J. Adhes. Adhes. 23269

15. Vu C 1989 US Patent 4859735A

16. Cardoso G T, Neto S C and Vecchia F 2012 Front. Architectural Res. 1348

17. Wang S and Min K 2010 Polymer 512621

18. Patton T C 1962 Alkyd resin technology (New York: Interscience) $p 1$

19. Petrovic Z S 2008 Polym. Rev. 48109

20. Smith B C 1998 Infrared spectral interpretation: a systematic approach (ed.) B C Smith (New York: CRC Press) p 91

21. Narine S S, Kong X, Bouzidi L and Sporns P $2007 \mathrm{~J} . \mathrm{Am}$. Oil Chem. Soc. 8465

22. Mortley A, Bonin H W and Bui V T 2007 Nucl. Instrum. Methods: Phys. Res. 26598 
23. Xu Y, Petrovic Z S, Das S and Wilkes G L 2008 Polymer 494248

24. Rashmi B J, Rusu D, Prashantha K, Lacrampe M-F and Krawczak P 2013 eXPRESS Polym. Lett. 7852

25. Badri K H 2012 Biobased polyurethane from palm kernel oil-based polyol (New York: InTech Publication) p 447 (Chapter 20)

26. Júnior J H S A, Bertuol D A, Meneguzzi A, Ferreira C A and Amado F D R 2013 Mater. Res. 16860

27. Liu D, Tian H, Zhang L and Chang P R 2008 Ind. Eng. Chem. Res. 479330
28. Yeganeh H and Shamekhi M A 2006 J. Appl. Polym. Sci. 991222

29. Corcuera M A, Rueda L, Saralegui A, Martín M D, Fernández-d'Arlas B, Mondragon I and Eceiza A 2011 J. Appl. Polym. Sci. 1223677

30. Su'ait M S, Ahmad A, Badri K H, Mohamed N S, Rahman M Y A, Ricardo C L A and Scardi P 2014 Int. J. Hydroenergy 393005

31. Ramesh S and Ang G P 2010 Ionics 16465

32. Ahmad A, Rahman M Y A, Low S P and Hamzah H 2011 ISRN Mater. Sci. Article ID 401280 